\title{
PHYLOGENETIC AFFINITIES OF ECHMATOCRINUS BRACHIATUS (MIDDLE CAMBRIAN BURGESS SHALE, CANADA)
}

AUSICH*, William I. and BABCOCK, Loren E., Dept. of Geological Sciences, The Ohio State University, Columbus, Ohio 43210, USA

The phylogenetic affinities of Echmatocrinus brachiatus, long considered to be the earliest crinoid, are reevaluated on the basis of morphology, preservation, and comparative anatomy. In recent years, the affinities of this organism, which is known only from the Burgess Shale quarries in the Stephen Formation (Middle Cambrian) of British Columbia, have become somewhat controversial. Alternative views of this organism are that it has either crinoid or cnidarian affinities.

Some characters of Echmatocrinus are consistent with an echinoderm (crinoid) interpretation, although viewed in another way they could be used to support a cnidarian (octocoral) interpretation. The conically shaped body of Echmatocrinus, together with the arms or tentacles that bear uniserial subdivisions, are perhaps the most convincing evidence of a crinoid affinity. However, modern octocorals may be conical and have tentacles. Putative plating covering the body of Echmatocrinus is traditionally interpreted as representing decalcified plates or spicules in the fossils. If they are decalcified plates, in many respects they are more similar to those on living plated octocorals (especially Primnoidae) than to recognized Cambrian and post-Cambrian echinoderms. The plates are highly irregular in shape and arrangement, and none can be homologized to the plates of

any Early Ordovician crinoid. Supposed stereom can be alternatively interpreted as surface ornamentation. As preserved, the body wall appears to have been soft and capable of some expansion or contraction during compaction. Relatively minor overlap among adjacent plates contrasts with the preservational style of Cambrian blastozoans and homalozoans. The solitary appearance of most known Echmatocrinus specimens is more consistent with a crinoid interpretation but does not rule out an octocoral interpretation. The rare occurrence of smaller specimens attached to a larger one is perhaps better interpreted as the result of budding rather than as epizoic behavior, but available evidence is inconclusive.

Of preserved characters, the number of arms and their morphology is probably the most definitive for distinguishing whether Echmatocrinus is a crinoid or octocoral. Among available specimens of $E$. brachiatus, none appears to have any more than eight arms. Assuming that additional arms were not originally present, the presence of eight arms accords better with a cnidarian affinity. Putative tube feet of $E$. brachiatus (reportedly the only tube feet preserved in any fossil echinoderm) closely resemble the pinnate divisions of modern octocoral tentacles.

Based on the lack of any definitive echinoderm characters, it seems best to remove Echmatocrinus from the Crinoidea and Echinodermata. Preserved characters suggest a closer affinity of this organism with cnidarians; $E$. brachiatus is tentatively interpreted as an early octocoral. 